\title{
Sensory Impairments and Delayed Regeneration of Sensory Axons in Interleukin-6-Deficient Mice
}

\author{
Jian Zhong, ${ }^{1}$ Irmgard D. Dietzel, ${ }^{1}$ Petra Wahle, ${ }^{2}$ Manfred Kopf, ${ }^{3}$ and Rolf Heumann ${ }^{1}$ \\ ${ }^{1}$ Lehrstuhl für Molekulare Neurobiochemie and 2Lehrstuhl für Allgemeine Zoologie und Neurobiologie, Ruhr-Universität \\ Bochum, 44780 Bochum Germany, and 3Max-Planck-Institut für Immunobiologie, Stübeweg 51, 79108 Freiburg, \\ Germany
}

Interleukin-6 (IL-6) is a multifunctional cytokine mediating inflammatory or immune reactions. Here we investigated the possible role of IL- 6 in the intact or lesioned peripheral nervous system using adult IL-6 gene knockout (IL- $6^{-/-}$) mice. Various sensory functions were tested by applying electrophysiological, morphological, biochemical, and behavioral methods. There was a $60 \%$ reduction of the compound action potential of the sensory branch of $1 \mathrm{~L}-6^{-/-}$mice as compared with the motor branch in the intact sciatic nerve. Cross sections of L5 DRG of IL- $6^{-/-}$mice showed a shift in the relative size distribution of the neurons. The temperature sensitivity of IL- $6^{-1-}$ mice was also significantly reduced.

After crush lesion of the sciatic nerve, its functional recovery was delayed in IL- $6^{-1-}$ mice as analyzed from a behavioral footprint assay. Measurements of compound action potentials $20 \mathrm{~d}$ after crush lesion showed that there was a very low level of recovery of the sensory but not of the motor branch of
IL- $6^{-/-}$mice. Similar results of sensory impairments were obtained with mice showing slow Wallerian degeneration $\left(\mathrm{Wld}^{\mathrm{s}}\right)$ and a delayed lesion-induced recruitment of macrophages. However, in contrast to $\mathrm{Wld}^{\mathrm{S}}$ mice, in IL-6 $6^{-1-}$ mice we observed the characteristic lesion-induced invasion of macrophages and the upregulation of low-affinity neurotrophin receptor p75 (p75LNTR) mRNA levels identical to those of IL-6 $6^{+/+}$ mice. Thus, the mechanisms leading to the common sensory deficiencies were different between $\mathrm{IL}-6^{-1-}$ and $\mathrm{WId}{ }^{S}$ mice. Altogether, the results suggest that interleukin- 6 is essential to modulate sensory functions in vivo.

Key words: interleukin-6; compound action potential; sensory fiber; motor fiber; temperature sensitivity; L5 DRG; neuron; sciatic functional index; regeneration; WId ${ }^{\text {; }}$; p75LNTR-mRNA; macrophages
Interleukin-6 (IL-6) is a pleiotrophic cytokine that mediates immune responses and inflammatory reactions affecting growth and differentiation (Hirano et al., 1997; Heinrich et al., 1998). In addition, IL-6 may play a key role in regulating neuronal survival and maintenance of functions (Gadient and Otten, 1997; Gruol and Nelson, 1997; Campbell, 1998). IL-6 belongs to the neuropoietic cytokine superfamily, which includes IL-11, ciliary neurotrophic factor (CNTF), leukemia inhibitory factor (LIF), oncostatin M (OSM), and cardiotrophin-1 (CT-1). All of these cytokines use the common signal-transducing receptor component gp130 (Ip et al., 1992; Pennica et al., 1995). The activation of the gp130 receptor is triggered by several types of receptorligand interactions, such as through the formation of the complex between the respective ligand and its specific extracellular membrane-anchored $\alpha$-receptor (IL-6, IL-11, CT-1, and CNTF) or by the direct interaction of the respective ligand and a membrane spanning LIF receptor- $\beta$ subunit (LIF, OSM). Further-

\footnotetext{
Received Jan. 19, 1999; revised March 15, 1999; accepted March 22, 1999.

This work was supported by the Deutsche Forschungsgemeinschaft. We thank Drs. B. Hengerer and H. Berns (Novartis, Basel, Switzerland) for help with the microscopical evaluation of DRG sections and P. Grafe (Munich) for advice on recording from peripheral nerves. The help by Dr. A. Markus in preparing this manuscript is greatly appreciated. The excellent technical assistance by Ms. I. Schorkowitz and Mr. R. Depping is acknowledged.

Correspondence should be addressed to Rolf Heumann, Lehrstuhl für Molekulare Neurobiochemie, NC7/174, Ruhr-Universität Bochum, 44780 Bochum, Germany.

Dr. Zhong's present address: Division of Biology, California Institute of Technology, Pasadena, CA 91125.

Copyright (C) 1999 Society for Neuroscience 0270-6474/99/194305-09\$05.00/0
}

more, OSM may bind and activate gp130 through another membrane-spanning $\beta$-receptor variant subunit (Akira et al., 1990; Kishimoto et al., 1992; for review see Hirano et al., 1997; Mehler and Kessler, 1997; Lindberg et al., 1998).

IL-6 is synthesized in a subpopulation of developing peripheral sensory and sympathetic neurons and in the developing CNS (Gadient and Otten, 1994, 1996; Murphy et al., 1995; März et al., 1998). In the adult nervous system IL-6 levels are hardly detectable, but IL-6 synthesis appears to be strongly increased during pathological situations (for review see Gadient and Otten, 1997; Vallières and Rivest, 1997). Thus, there is a lesion-induced elevation of IL-6 mRNA in the non-neuronal cells surrounding the motor fibers of the facial nucleus after motoneuron axotomy (Kiefer et al., 1993), and similarly, an increase in IL-6 synthesis is found in the sciatic nerve at sites undergoing Wallerian degeneration (Bolin et al., 1995; Zhong and Heumann, 1995; Bourde et al., 1996; Kurek et al., 1996; Reichert et al., 1996). In addition, sciatic nerve injury stimulates IL-6 synthesis in the cell bodies of certain dorsal root sensory neurons within $1 \mathrm{~d}$ (Murphy et al., 1995).

The role of IL- 6 in the nervous system is not resolved because beneficial as well as destructive actions have been described. Transgenic overexpression of IL-6 in astrocytes induced cellular neuropathological changes indicating a chronic inflammatory response leading to motor impairment and seizures (Campbell et al., 1993; Campbell, 1998). Other studies show that IL-6 promotes survival in peripheral and central neurons (Hama et al., 1991; Kushima and Hatanaka, 1992; Kushima et al., 1992; Ikeda et al., 1996; Murphy et al., 1997; März et al., 1998), and IL-6 may 
cooperate with high-affinity neurotrophin receptor Trk signaling mechanisms (Sterneck et al., 1996).

In this study we investigated the possible supportive or destructive role of IL- 6 in the maintenance of function and regeneration of peripheral neurons. We combined behavioral studies, electrophysiological measurements, immunohistochemical methods, and morphometric analysis as well as biochemical investigations on the intact or lesioned rat sciatic nerve of IL-6-deficient (IL- $6^{-1-}$ ) mice (Kopf et al., 1994). We show that in IL- $6^{-1-}$ mice sensory functions are impaired in the intact adult animals and that the regeneration of the lesioned sensory axons is delayed. In an approach to understanding the underlying mechanism, we compared the results obtained from IL- $6^{-1-}$ mice with those of Wld ${ }^{S}$ (previously called C57BL/6-Ola) mice. Wld ${ }^{\mathrm{S}}$ mice had previously been shown to develop a strong delay in the lesion-induced recruitment of IL-6-producing macrophages (Lunn et al., 1989; Akira and Kishimoto, 1996). Thus we anticipated that the reduced IL-6 supply in lesioned Wld ${ }^{\mathrm{S}}$ mice could result in an IL-6 $6^{-1-}$-like phenotype (Brown et al., 1991; Reichert et al., 1996).

\section{MATERIALS AND METHODS}

Animals and surgical procedures. Adult (16 weeks or older) IL- $6^{+/+}$and IL-6 $^{-1-}$ mice (IL-6 ${ }^{+/+}:$F2:C57BL/6 $\times$Sv129:IL- $6^{+/+}$, IL-6 ${ }^{-/-}:$F2: C57BL/6×Sv129:IL-6 ${ }^{-1-}$; Max-Planck-Institute for Immunobiology, Freiburg, Germany) and C57BL/6 and C57BL/6- Wld ${ }^{\mathrm{S}}$ mice (Harlan Winkelmann, Borchen, Germany) were used for the experiments.

Mice were deeply anesthetized with ether. For the investigation of the functional regeneration, the sciatic nerves were exposed, desheathed of connective tissue, and then crushed unilaterally three times at the upper thigh position using fine forceps, the tips of which had been cooled in liquid $\mathrm{N}_{2}$ before use (Heumann et al., 1987a). The site of lesion was marked with sterile coal powder for later identification. The wounds were closed with fine clips (ep0.5), which were removed $3 \mathrm{~d}$ after operation.

Measurement of compound action potentials. Intact or lesioned sciatic nerves were completely dissected from spinal roots at L5 to the ankle (tibial nerve) in an ice-cold bath solution ( $4 \mathrm{~mm} \mathrm{KCl}, 145 \mathrm{~mm} \mathrm{NaCl}, 3 \mathrm{~mm}$ $\mathrm{CaCl}_{2}, 2 \mathrm{~mm} \mathrm{MgCl}_{2}, 10 \mathrm{~mm}$ HEPES, $10 \mathrm{~mm}$ glucose, $\mathrm{pH}$ 7.3) $20 \mathrm{~d}$ after crush. The measurements were then performed at room temperature $\left(20-25^{\circ} \mathrm{C}\right)$ in the same bath solution using a perspex chamber partitioned into 14 compartments as schematically shown in Figure $1 A$. The compartments had a length of $4 \mathrm{~mm}$ and a depth of $5 \mathrm{~mm}$. Extracellular compound action potentials (CAPs) were recorded differentially between positions 12 and 14, from either the dorsal (sensory) or the ventral (motor) branch. All saline-filled compartments were connected to chlorided silver electrodes $(4 \mathrm{~mm}$ inter-electrode distance along the sciatic nerve and $3.5 \mathrm{~mm}$ in the sensory and motor branches). Recording electrodes were connected to a differential recording amplifier (Jens Meyer Technical Developments). The distal ends of the nerves were stimulated with square pulses of $4 \mathrm{~V}$ and $30 \mu \mathrm{sec}$ duration (SD9, Grass). The ground electrode was positioned proximally to the stimulating electrodes. To test for the distance of successful regeneration, the ensemble of the ground and stimulating electrodes was moved from the sciatic bifurcation distally along the nerve in successive steps of $4 \mathrm{~mm}$. Under our recording conditions the maximal amplitudes of the CAPs of the sensory or motor fibers varied from 1 to $6 \mathrm{mV}$ when the stimulation was applied $4 \mathrm{~mm}$ distal to the sciatic bifurcation (position 9/10). The speed of action potential propagation in the intact myelinated axons was $\sim 30 \mathrm{~m} / \mathrm{sec}$ at room temperature $\left(20-25^{\circ} \mathrm{C}\right)$. The threshold for most excitable myelinated axons was $<1 \mathrm{~V}$. Refractory properties were tested by applying twin pulses with identical stimulus parameters using a time interval of $3.6 \mathrm{msec}$. Because the interpulse interval was within the relative refractory period, the second CAP showed a reduced amplitude compared with the CAP evoked by the first pulse. As a measure of the refractory properties the ratio of the amplitudes of the second pulse to the first pulse was determined. Data were low-pass-filtered at $3 \mathrm{kHz}$, digitized with a Digidata $1200 \mathrm{~A} / \mathrm{D}$-converter, and further processed with PClamp 6 (Axon Instruments) and AUTES P software (Garching Instruments). CAPs were averaged up to 10 times and recorded within 30 min after dissection.

Temperature sensitivity assay (hot-plate assay). Sensitivity to heat was tested by letting the paws of the mice touch an aluminum hot plate set to $60^{\circ} \mathrm{C}$ for no more than $20 \mathrm{sec}$. The time interval until the mice first lifted the forepaws was recorded. This procedure resulted in no recognizable injury to the heat-exposed skin.

Histological sections. L5 DRGs were dissected out of nonlesioned adult IL $-6^{+/+}$and IL- $6^{-1-}$ mice perfused with $4 \%$ paraformaldehyde. They were immersed in 30\% sucrose solution and embedded in Tissue Tek (Miles, Elkhart, IN) for cryostat sections. Serial sections (16 $\mu \mathrm{m}$ thick) were made throughout the length of the DRGs from three IL- $-6^{+/+}$and three IL- $6^{-1-}$ mice (Cryostat, Reichert and Jung). They were then mounted for microscopy after Nissl staining. In the cross sections, soma areas of sensory neurons containing a clearly visible nucleus and more than one nucleolus were evaluated under a microscope using the Microcomputer Image Device program (Imaging Research).

Sciatic functional index. Footprints of mice were recorded in a 90$\mathrm{cm}$-long and 8-cm-wide runway on plain film (Cronaflex U-C drafting film, DuPont) after the hindpaws had been painted with black ink. Before the actual experiment, the animals were trained to walk through the runway several times. The traces left by the mice were measured in $3 \mathrm{~d}$ intervals from day 3 to day 30 after crush. The recovery of sciatic nerve function was then quantified as described by De Medinaceli et al. (1982).

Northern blots. Sciatic nerves of adult mice were desheathed from connective tissue and then transected in the uppermost thigh position, and the distal end of the axotomized nerve was deflected to minimize nerve regeneration. The wound was closed with surgical clips. Four days after axotomy the animals were killed by cervical dislocation, and the distal nerve was divided into 10 -mm-long nerve segments. In all preparations, $\sim 1 \mathrm{~mm}$ of nerve adjacent to the lesion site was discarded because of the localized macrophage invasion in this area in the Wld ${ }^{\mathrm{S}}$ mice (Brown et al., 1991). Nonlesioned nerve segments were isolated in a similar manner. After addition of $100 \mathrm{pg}$ cRNA derived from a truncated cDNA of murine nerve growth factor (NGF), total RNA was isolated from pooled nerve segments of four animals as described elsewhere (Chomczynski and Sacchi, 1987; Heumann et al., 1987a). Rat p75 lowaffinity neurotrophin receptor (p75LNTR) and murine NGF antisense cRNA probes labeled with ${ }^{32} \mathrm{P}-\alpha \mathrm{UTP}$ (NEN) were generated using T3 or T7 RNA polymerase (MBI Fermentas). Northern blots were hybridized overnight at $68^{\circ} \mathrm{C}$ in hybridization solution $[5 \mathrm{ml}$ formamide, $100 \mu \mathrm{l}$ salmon sperm DNA $(10 \mu \mathrm{g} / \mathrm{ml}), 1 \mathrm{ml} 50 \times$ Denhardt's solution, $125 \mu \mathrm{l} 0.2$ $\mathrm{M} \mathrm{Na}_{2} \mathrm{HPO}_{4}, 125 \mu \mathrm{l} 0.5 \mathrm{M} \mathrm{NaH}_{2} \mathrm{PO}_{4}, 2.5 \mathrm{ml} 20 \times$ SET ( $3 \mathrm{M} \mathrm{NaCl}, 400 \mathrm{~mm}$ Tris-HCl, pH 7.8, $20 \mathrm{~mm}$ EDTA), $250 \mu \mathrm{l} 10 \%$ SDS] in a total of $10 \mathrm{ml}$ $\mathrm{H}_{2} \mathrm{O}$ and washed $8-12 \mathrm{hr}$ at $68^{\circ} \mathrm{C}$ in wash solution $(0.1 \times$ SET, $0.1 \%$ SDS). Films (Fuji RX) were exposed using Dr. Goos 200 intensifying screen at $-80^{\circ} \mathrm{C}$ for $12-24 \mathrm{hr}$. For evaluation of the relative mRNA levels, Northern blots were exposed on phosphorimaging plates and analyzed with a Fujix BAS1000 Phosphorimager using the TINA 2.0 software (Raytest). CRNA fragments coding for NGF were used as an internal standard as described previously (Heumann et al., 1987a) (data not shown).

Macrophage staining and counting. Four days after cut lesion, $5 \mathrm{~mm}$ pieces of the nerve taken from a region located at least $2 \mathrm{~mm}$ distal to the cut were dissected and embedded in Tissue Tek. Sections were cut $16 \mu \mathrm{m}$ thick on a cryostat (Leica CM3050) and placed on coated slides (Superfrost Plus, Fisher Scientific, Houston, TX). Sections were blocked with $2 \%$ goat serum in PBS, and macrophages were labeled with monoclonal antibody F4/80 (Austyn and Gordon, 1981) and the ABC-AP-kit (Vector Laboratories, Burlingame, CA). For detection of the reaction product, slices were developed with nitroblue tetrazolium $(450 \mu \mathrm{l}, 75 \mathrm{mg} / \mu \mathrm{l})$ and 5-bromo-4-chloro-3-indoyl-phosphate $(350 \mu \mathrm{l}, 50 \mathrm{mg} / \mu \mathrm{l})$ in $100 \mathrm{ml}$ APbuffer ( $0.1 \mathrm{M} \mathrm{NaCl}, 50 \mathrm{~mm} \mathrm{MgCl} 2,0.1 \mathrm{M}$ Tris- $\mathrm{HCl}, \mathrm{pH} 9.5)$, following the manufacturer's instructions. Nonlesioned contralateral sciatic nerve segments of the same animals were used as negative controls. All counts were expressed as the number of positive-stained cells per square millimeter.

\section{RESULTS}

\section{Measurements in the intact animals}

\section{Reduced sensory compound action potentials}

CAPs of myelinated nerve fibers from adult mice were recorded separately from the motor and sensory branches proximal to the bifurcation of the sciatic nerve to determine the CAP evoked at each point along the nerve. Figure $1 B$ shows a series of such CAP 

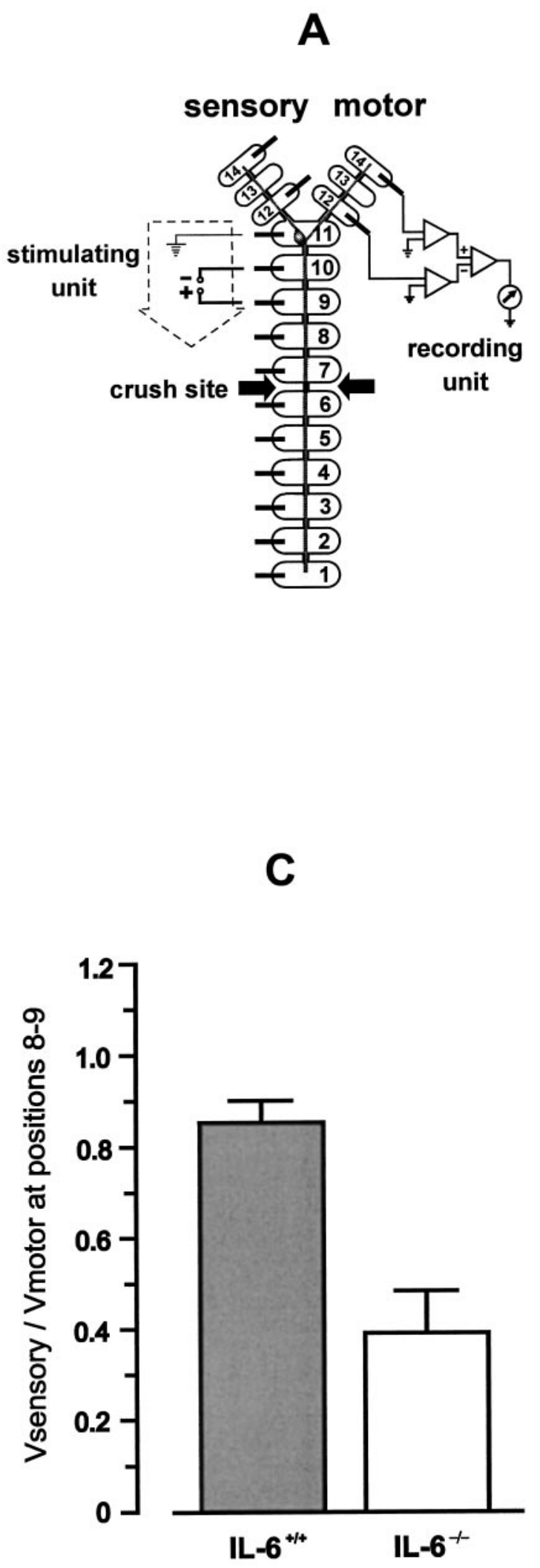

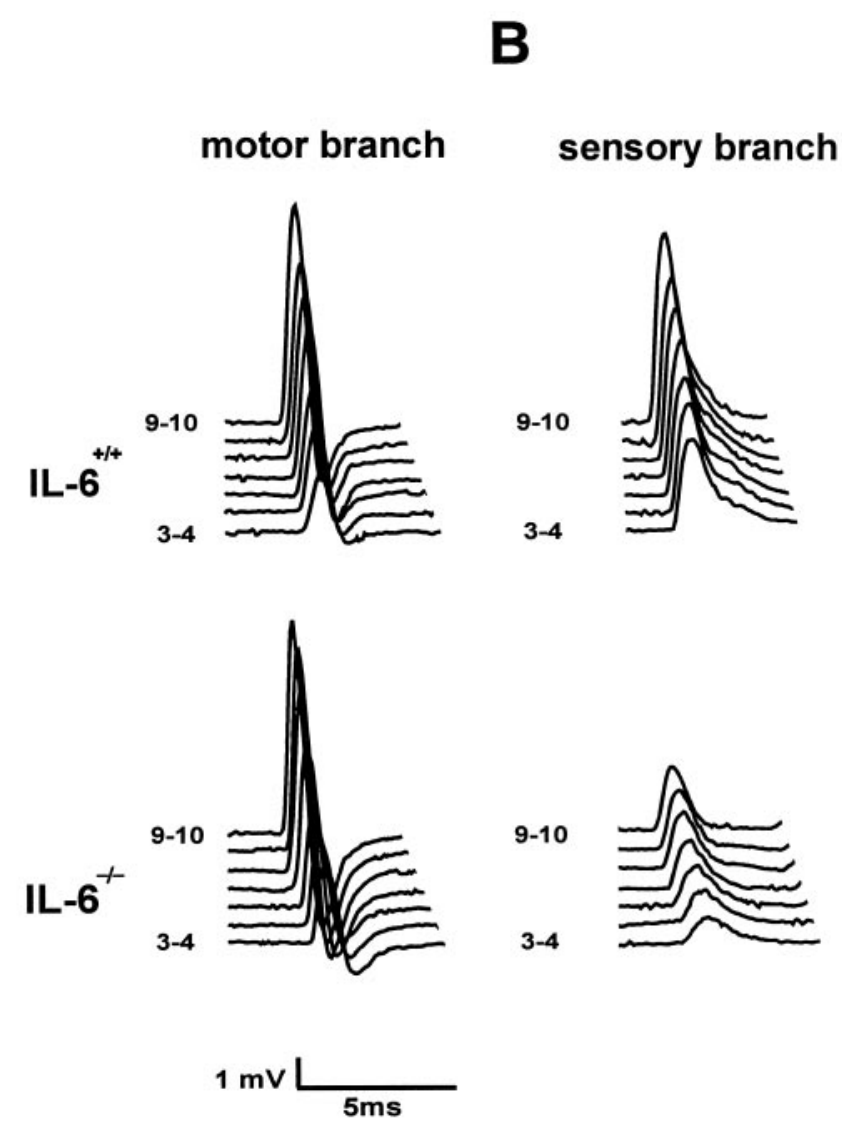

Figure 1. Recordings of compound action potentials (CAPs) selectively measured from sensory or motor branches of the sciatic nerve. A. Schematic drawing of the recording chamber and the positions of the recording electrodes (symbolized by the differential amplifier icons) as well as stimulating electrodes (symbolized by the stippled arrow on the left). B, CAPs recorded from sensory and motor branches of IL $-6^{+/+}$and IL- $6^{-1-}$ mice. The series of recordings was obtained by successive stimulations starting at the position $4 \mathrm{~mm}$ distal to the bifurcation (9/10). Between stimulations, the stimulating unit was moved at steps of $4 \mathrm{~mm}$ from the sciatic bifurcation in the distal direction along the nerve until reaching the final position 3-4. C, Ratio between amplitudes of CAPs derived from sensory versus motor branches. Gray column, IL $-6^{+/+}$mice; white column, IL $-6^{-1-}$ mice. The stimulating unit was positioned at compartments $8 / 9$ as indicated in $A$ (IL- $6^{+/+}$mice, $n=10$; IL-6 $6^{-/-}$mice, $\left.n=10 ; p<0.005\right)$. records obtained from the sciatic nerves of IL- $6^{+/+}$and IL- $6^{-/-}$ mice. Although sensory and motor CAPs of all measured IL- $6^{+/+}$ mice were of similar amplitudes, the sensory CAPs in the knockout mice were consistently smaller than the motor CAPs (Fig. $1 B)$. Because the amplitudes of CAPs between individual animals varied between 1 and $6 \mathrm{mV}$, we normalized the amplitude of sensory CAPs elicited by stimulation at position $8 / 9$ of the chamber (Fig. $1 A$ ) to that of motor CAPs in the same nerve evoked by a stimulus of the same parameters. This facilitated comparison of sensory to motor CAPs in the various strains of mice. We refer to 


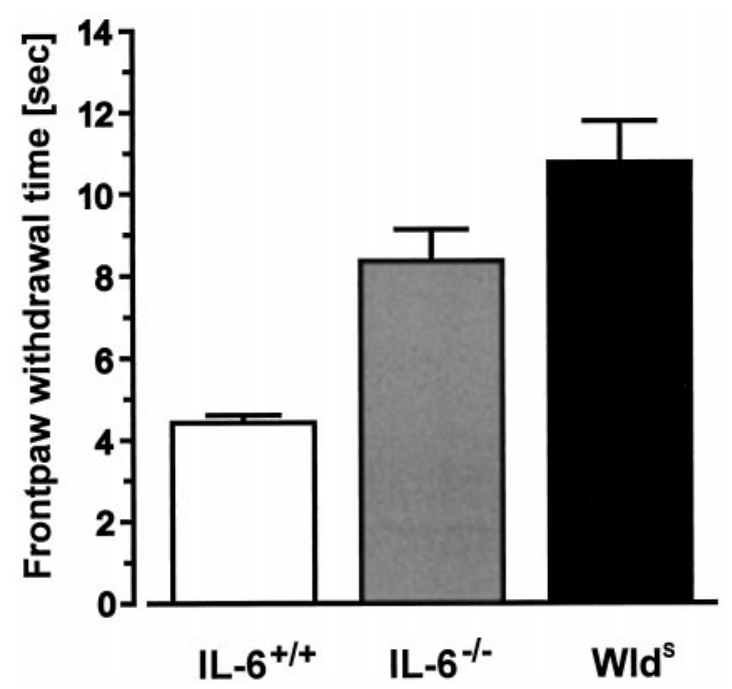

Figure 2. Temperature sensitivities as measured by the frontpaw withdrawal time. White column, IL-6 $6^{+/+}$mice; gray column, IL-6 ${ }^{-/-}$mice; black column, Wld ${ }^{\mathrm{s}}$ mice. The time intervals until a mouse first lifted the forepaws from a plate, set at $60^{\circ} \mathrm{C}$, were recorded.

this ratio as "relative sensory amplitude" ( $\mathrm{RSA}_{8 / 9}$ :amplitude sensory

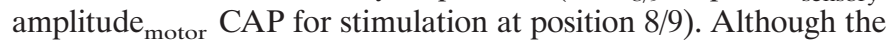
sensory CAPs were of magnitude comparable to those of the motor CAPs in IL- $6^{+/+}$mice $\left(\mathrm{RSA}_{8 / 9}=0.85 \pm 0.05, n=10\right)$, the $\mathrm{RSA}_{8 / 9}$ in IL- $6^{-1-}$ mice was $0.40 \pm 0.09(n=10)$, which is significantly smaller (Fig. 1C) $(p<0.005$, Student's $t$ test). With increasing distances of the stimulating electrodes from the sciatic bifurcation into the periphery, the amplitudes of CAPs decreased because of the decreasing number of fibers toward the periphery (Fig. 1B).

Reduced temperature sensitivity in IL-6 ${ }^{-1-}$ and $\mathrm{Wld}^{S}$ mice

Because the IL- $6^{-/-}$mice showed reduced amplitudes of sensory action potentials we investigated whether these mice also show phenotypic sensory impairments as compared with the IL- $6^{+/+}$ mice. In the hot-plate assay a reduced temperature sensitivity was seen in IL- $6^{-1-}$ mice (Fig. 2). The mean paw withdrawal time of IL- $6^{+/+}$mice was $4.4 \pm 0.25 \mathrm{sec}(n=54)$, whereas IL- $6^{-/-}$and $\mathrm{Wld}^{\mathrm{S}}$ mice took almost twice that time to react to the same heat exposure $(8.4 \pm 0.9 \mathrm{sec}, n=32, p \leq 0.005 ; 10.8 \pm 1.1 \mathrm{sec}, n=21$, $p \leq 0.005$, respectively).

\section{Changes of the size distribution of L5 DRG neurons in} IL-6 ${ }^{-/-}$mice

To characterize a possible morphological basis of the sensory defect in IL-6 $6^{-1-}$ mice, cross sections of L5 DRGs were made and quantitatively evaluated. Soma areas of DRG neurons from both strains of mice were counted in sections. The histogram in Figure 3 represents the relative distribution of cell soma sizes in IL $-6^{+/+}$and IL- $6^{-/-}$mice. All DRG sections of three animals of IL- $6^{+/+}$and IL- $6^{-/-}$mice were pooled, and a total number of 2053 neurons from IL- $6^{+/+}$mice and 1815 neurons from IL- $6^{-/-}$ mice were evaluated. The population of neurons with a crosssectional area $>700 \mu \mathrm{m}^{2}$ was reduced from $\sim 32 \%$ in $\mathrm{IL}-6^{+/+}$to $17 \%$ in IL- $6^{-/-}$mice.

\section{Investigations on crush-lesioned animals}

Sciatic functional index (footprint assay)

The functional recovery of lesioned sciatic nerves was quantified between 1 and $30 \mathrm{~d}$ after crush to determine the sciatic functional

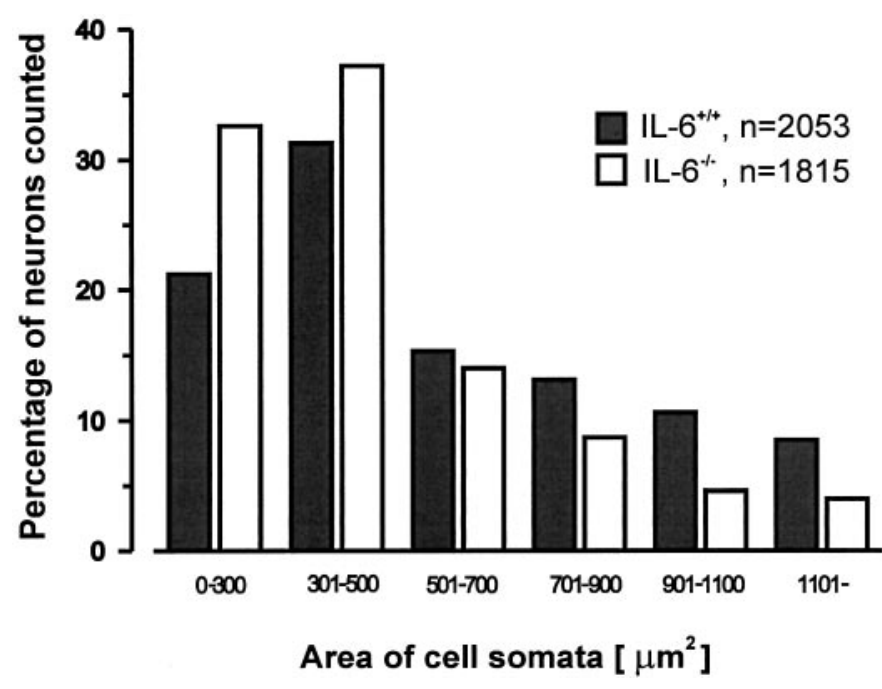

Figure 3. Relative size distributions of L5 DRG neurons in IL- $6^{+/+}$and IL- $6^{-1-}$ mice. The size of neuronal somata was obtained from stained cross sections of the L5 DRGs. A total number of 2053 cells from IL-6 ${ }^{+/+}$ ( gray columns) and 1815 cells from IL-6 $6^{-1-}$ mice (white columns) were evaluated.

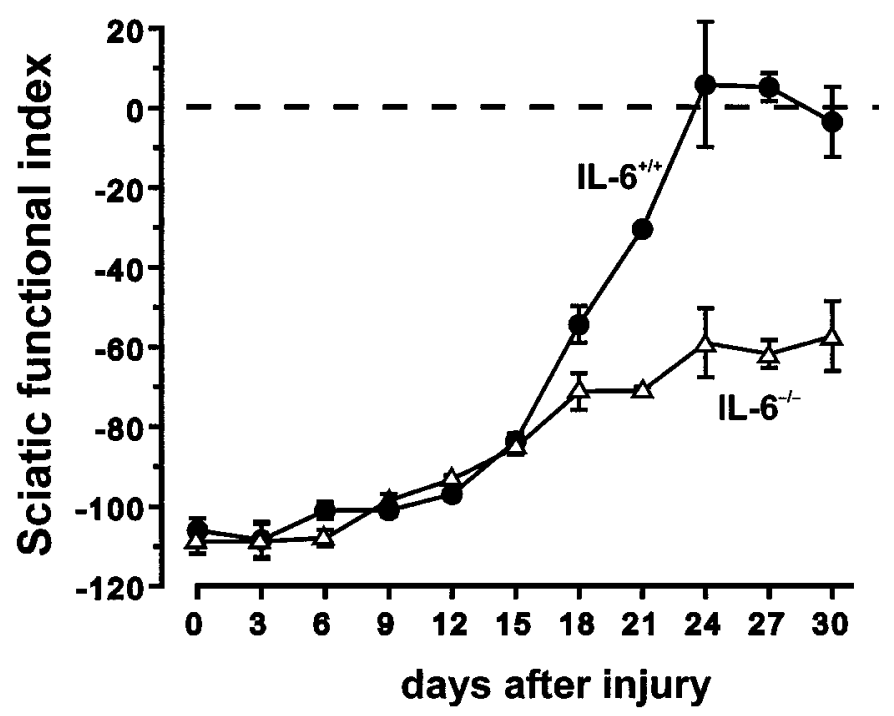

Figure 4. Sciatic functional index (SFI) for the regeneration of crushlesioned sciatic nerve. IL- $6^{+/+}$mice $(\bigcirc)$; IL-6 $6^{-/-}(\triangle)$ mice (error bars indicate SD).

index (SFI) (Fig. 4). The SFI was identical between IL- $6^{+/+}$and IL- $6^{-1-}$ mice up to $15 \mathrm{~d}$ after lesion and increased only slightly from approximately -110 (arbitrary units) to -90 . Thereafter, IL- $6^{+/+}$mice rapidly recovered and reached the normal value (zero for nonlesioned mice) approximately $24 \mathrm{~d}$ after lesion. The recovery of the sciatic function in IL- $6^{-1-}$ mice was much slower and attained an SFI value of only approximately -60 after $30 \mathrm{~d}$, the longest time period investigated.

\section{Conduction velocities of compound action potentials in} the nerve

In intact myelinated sciatic nerve the conduction velocity was $\sim 25-30 \mathrm{~m} / \mathrm{sec}$ at room temperature (Table 1). No significant difference between the two strains of mice was detectable. In regenerating nerves the propagation of the CAP was slower, in 


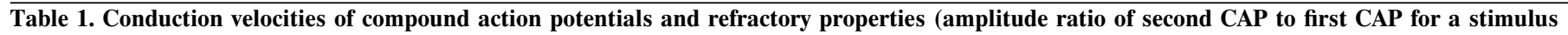
interval of $3.6 \mathrm{msec}$ ) in nonlesioned and lesioned sciatic nerves

\begin{tabular}{|c|c|c|c|c|c|c|c|}
\hline & \multirow{2}{*}{$\begin{array}{l}\text { Type of } \\
\text { mouse }\end{array}$} & \multicolumn{3}{|c|}{ Conduction velocities } & \multicolumn{3}{|c|}{ Relative amplitude ratio for double pulses (RFP) } \\
\hline & & Sensory & Motor & $n$ & Sensory & Motor & $n$ \\
\hline \multirow[t]{2}{*}{ Nonlesioned } & $\mathrm{IL}-6^{+/+}$ & $25.8 \pm 8.7$ & $27.0 \pm 9.1$ & 18 & $0.53 \pm 0.23$ & $0.61 \pm 0.15$ & 15 \\
\hline & IL $-6^{-/-}$ & $26.4 \pm 12.0$ & $28.7 \pm 13.0$ & 12 & $0.63 \pm 0.11$ & $0.54 \pm 0.19$ & 15 \\
\hline \multirow[t]{2}{*}{ Lesioned (proximal) } & $\mathrm{IL}-6^{+/+}$ & $30.0 \pm 9.0$ & $25.3 \pm 4.1$ & 14 & $0.50 \pm 0.15$ & $0.58 \pm 0.09$ & 12 \\
\hline & IL $-6^{-/-}$ & $25.8 \pm 10.4$ & $24.0 \pm 6.1$ & 11 & $0.50 \pm 0.16$ & $0.54 \pm 0.21$ & 6 \\
\hline \multirow[t]{2}{*}{ Lesioned (distal) } & IL $-6^{+/+}$ & $7.2 \pm 2.4$ & $7.5 \pm 2.0$ & 21 & $0.31 \pm 0.13$ & $0.23 \pm 0.16$ & 15 \\
\hline & IL $-6^{-/-}$ & $6.2 \pm 2.4$ & $6.4 \pm 1.8$ & 7 & $0.28 \pm 0.14$ & $0.26 \pm 0.19$ & 6 \\
\hline
\end{tabular}

motor branch

(A) IL-6 ${ }^{+/+}$

(B) IL-6

9-10

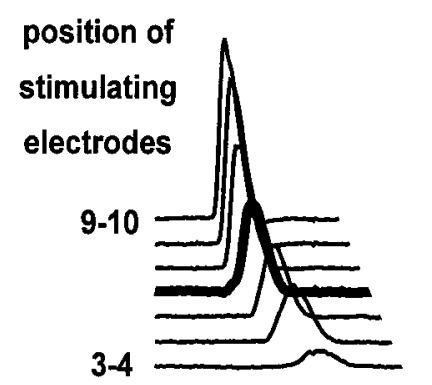

3-4

\section{sensory branch}

9-10
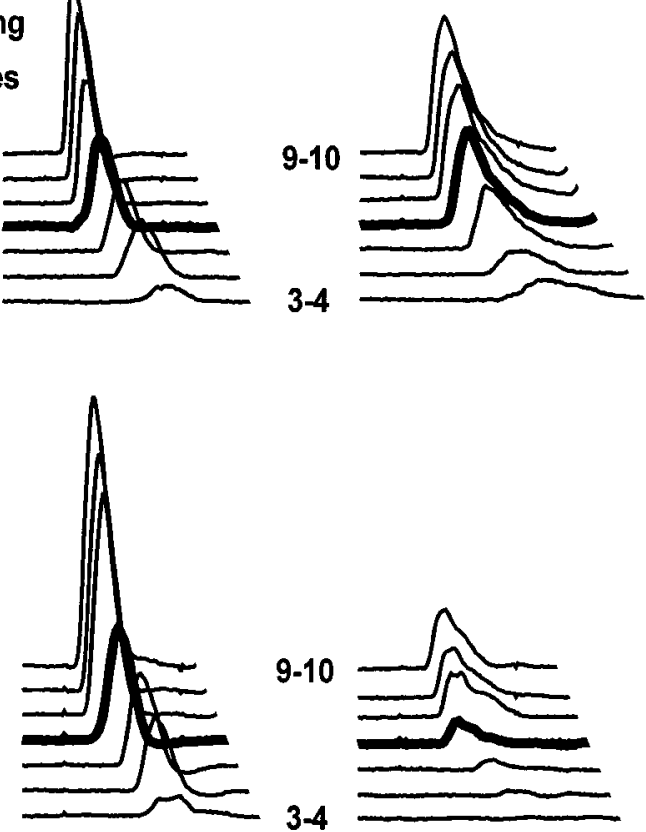

$9-10$

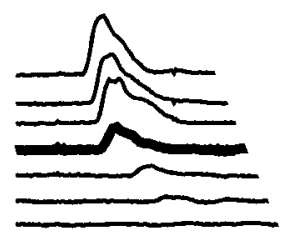

\section{(C) C57BL/6/WId}

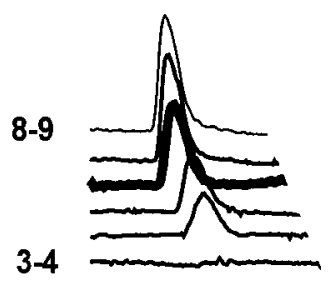

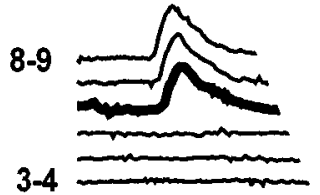

$1 \mathrm{mV}$
Figure 5. Regeneration of motor and sensory branches $20 \mathrm{~d}$ after crush lesion. Series of recordings of CAPs in sensory and motor branches of IL- $6^{+/+}$, IL $-6^{-1-}$, and Wld ${ }^{\mathrm{S}}$ mice. CAPs elicited by stimulation at the positions indicated at the left of the traces and recorded at positions 12/14 of sensory and motor branches (see Fig. $1 A$ ). The crush site was positioned between chambers 6 and 7 (bold trace). 
motor branch

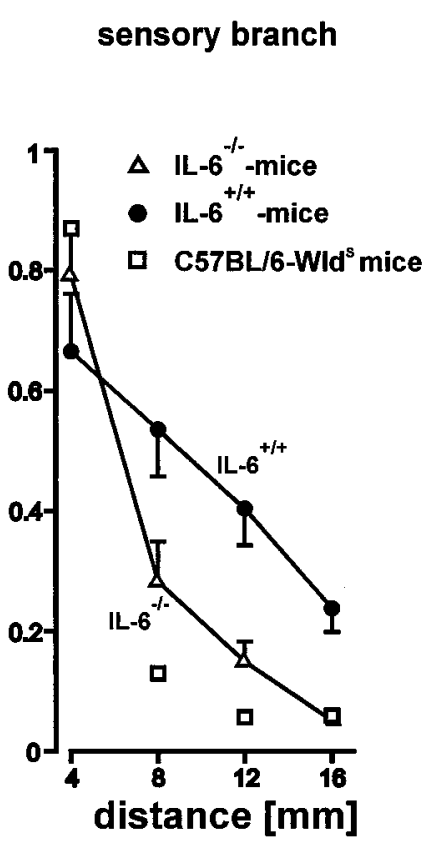

Figure 6. Spatial decrement of CAPs of sensory and motor branches of regenerating sciatic nerves $20 \mathrm{~d}$ after crush lesion $\left(\bullet\right.$, IL- $6^{+/+}$mice, $n=$ 4; $\triangle$, IL $-6^{-1-}$ mice, $n=4$; $\square$, Wld ${ }^{\mathrm{S}}$ mice, $\left.n=2\right)$. Error bars indicate SD. Amplitudes of CAPs elicited by stimulation at successive distal positions $\left(V_{\text {dis }}\right)$ normalized to CAP amplitudes evoked by stimulation at position $6 / 7\left(\right.$ crush site $\left.=V_{\mathrm{o}}\right)$.

motor as well as sensory branches of IL- $6^{-1-}$ mice as well as IL- $6^{+/+}$mice. This finding is consistent with results obtained previously in regenerating nerves and can be explained by decreased distances of Ranvier nodes of the newly outgrowing fibers (Ritchie, 1982). In both IL-6 $6^{+/+}$and IL-6 ${ }^{-/-}$mice, twin pulses with an interpulse interval of $3.6 \mathrm{msec}$ regularly evoked a second CAP with a reduced amplitude (Table 1). Because regenerating nerves of both IL- $6^{+/+}$and IL- $6^{-/-}$mice responded with a similar increase in refractoriness to a second stimulus of equal parameters than intact nerves, this suggests that no obvious differences in ion channel regulation occur in the distal stumps of both types of mice.

\section{Impaired recovery of sensory compound action potentials after} crush lesion

CAPs were recorded separately from dorsal and ventral roots after lesion. A slower recovery of CAPs was recorded in the sensory branch in IL- $6^{-/-}$mice as compared with the IL- $6^{+/+}$ mice $20 \mathrm{~d}$ after crush (Fig. 5). At this time point in IL- $6^{+/+}$mice the CAPs in the motor branch as well as in the sensory branch were detectable even if the nerve was stimulated at the distal positions $3 / 4, \sim 12 \mathrm{~mm}$ distant from the crush site of the sciatic nerve. In nerves from IL- $6^{-/-}$mice, a comparable amplitude of CAPs in the motor branch could be recorded at position $3 / 4$, but almost no sensory CAP was detectable if they were stimulated at the same position (Fig. 5B). For a comparison of the spatial decrements of sensory and motor CAPs from different animals, the amplitudes of the CAPs obtained for the various distal points of stimulation were normalized to the amplitude of the CAP evoked by stimulation at the crush site (Fig. $5 A-C)\left(V_{\mathrm{o}}=\right.$ stimulation at site $6 / 7$; bold trace, $V_{\mathrm{dis}}=$ stimulation at sites distal to the crush site). As shown in Figure $5 B$ the spatial decrement of CAPs of the motor branches of IL- $6^{-1-}$ mice was not different from

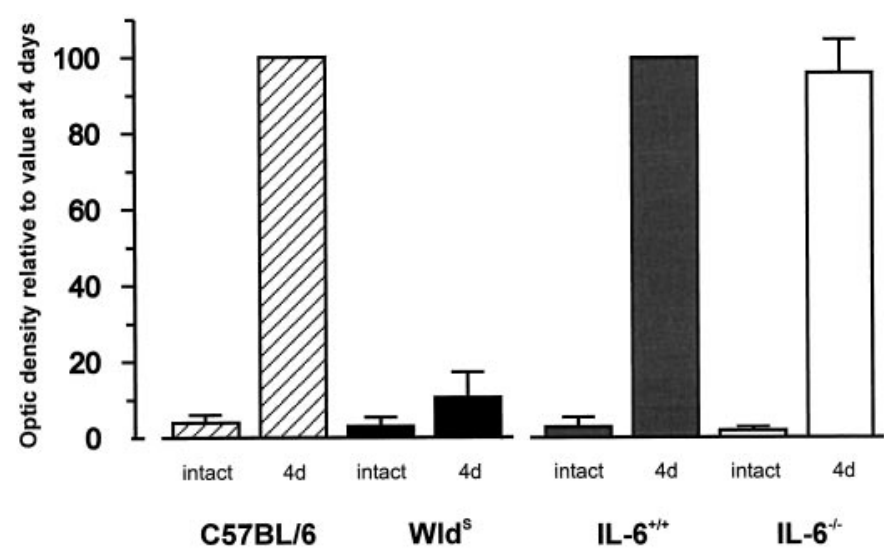

Figure 7. Northern blot quantifications of p75LNTR mRNA levels. Samples were measured from nonlesioned and lesioned sciatic nerves of C57BL/6 (stippled column), C57BL/Wld ${ }^{\text {S }}$ (black column), IL-6 ${ }^{+/+}$( gray column), and IL- $6^{-1-}$ (white column) mice $4 \mathrm{~d}$ after transsection; means of three independent experiments. Error bars indicate SD. Signals were quantified by using a Phosphoimager BAS 100 (Fuji). Values were normalized to $\mathrm{C} 57 \mathrm{BL} / 6$ as controls for $\mathrm{Wld}^{\mathrm{S}}$ mice and to $\mathrm{IL}-6^{+/+}$mice as controls for IL $-6^{-1-}$ mice.

those of IL- $6^{+/+}$mice. In contrast, the sensory CAP showed an enhanced decay in IL- $6^{-/-}$mice as compared with the IL- $6^{+/+}$ mice, suggesting a selective impairment of sensory regeneration (Figs. 5, 6).

The Wld $^{\mathrm{S}}$ mice showed defects in sensory regeneration similar to those of IL- $6^{-/-}$mice. The spatial decrements of the sensory CAPs were even more impaired than in the IL- $6^{-/-}$ mice (Figs. 5, 6).

\section{Comparison of the p75LNTR mRNA level in IL-6 ${ }^{-1-}$ and Wld $^{S}$ mice}

A very low level of p75mRNA was shown in nonlesioned nerve segments of all strains. Four days after lesion the mRNA level of p75LNTR was strongly upregulated in sciatic nerve segments 1 $\mathrm{cm}$ distal to the cut site in C57BL/6, in IL- $6^{+/+}$mice and in IL-6 $6^{-1-}$ mice (Fig. 7). In Wld ${ }^{\mathrm{S}}$ mice only a slight upregulation was shown, confirming our previous observation (Brown et al., 1991). Note that there was no difference in p75LNTR mRNA levels between IL- $6^{+/+}$and IL- $6^{-/-}$mice.

\section{Macrophage invasion in lesioned sciatic nerves}

At $4 \mathrm{~d}$ after sciatic nerve lesion, the number of macrophages rose from undetectably low numbers in intact nerves to the characteristically high numbers in IL- $6^{+/+}$mice $\left(275 \pm 20 / \mathrm{mm}^{2}\right)$ and IL- $6^{-1-}$ mice $\left(263 \pm 22 / \mathrm{mm}^{2}\right)$, as quantified by counting F4/80 positive cells from three sections of two animals each (Fig. 8). Thus, the invasion of macrophages was apparently not impaired in IL-6 $6^{-1-}$ mice. In accordance with previous results, macrophage invasion was strongly delayed in Wld ${ }^{\mathrm{S}}$ mice.

\section{DISCUSSION}

IL-6 belongs to the neuropoietic cytokines that mediate cellular reactions of inflammation and immune response (Hirano et al., 1986, 1997; Heinrich et al., 1998; Ramsay and Kopf, 1998). IL-6 is expressed in the developing nervous system and its synthesis is strongly induced during pathological situations from barely detectable levels in the adult nervous system (Vallières and Rivest, 1997). Using adult IL- $6^{-1-}$ mice as a model, we now describe 


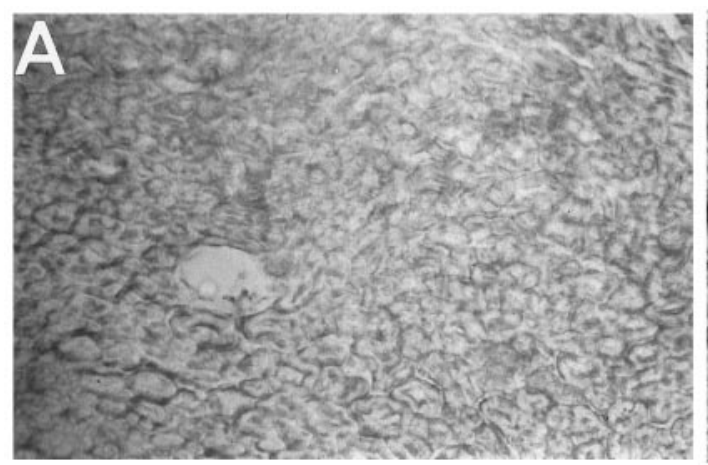

non-lesioned $\left(\mathrm{IL}-6^{+/+}\right)$

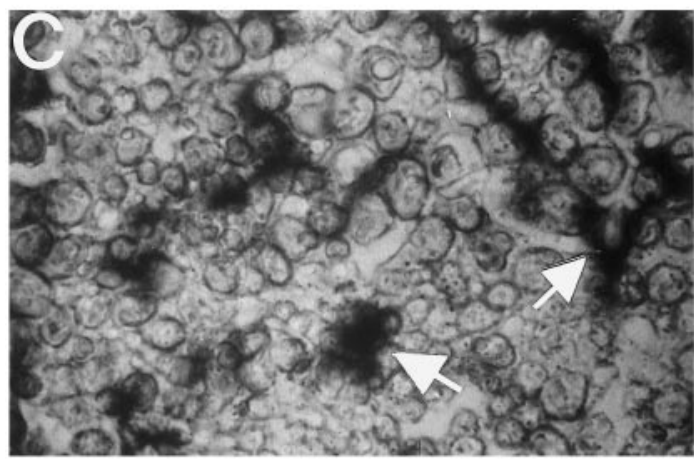

4 days after transection (IL- $6^{+/+}$)

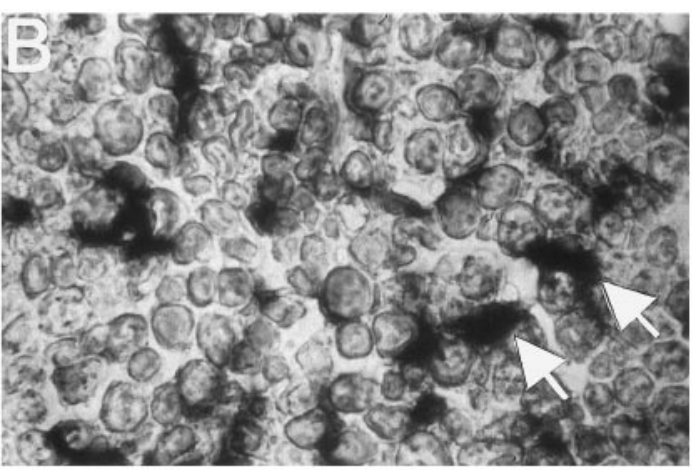

4 days after transection (IL-6 $6^{-1}$ )

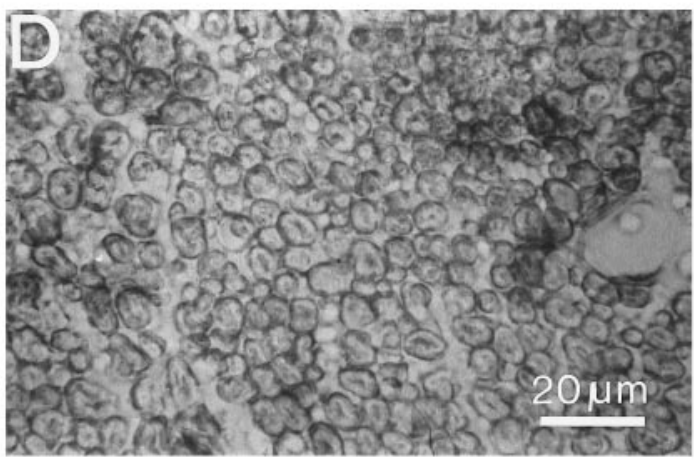

4 days after transection (C57BL/6/WId ${ }^{5}$ )

Figure 8. Immunohistochemical staining of macrophages in sciatic nerve using F4/80 antibody. $A$, Cross section of nonlesioned nerve of a C57BL/6 wild-type mouse; $B-D$, cross sections of transsected nerve segments within $5 \mathrm{~mm}$ distal to the cut site, $4 \mathrm{~d}$ after lesion. $B$, Nerve segment of an IL-6 ${ }^{-1-}$ mouse. $C$, Nerve segment of an IL $-6^{+/+}$mouse. $D$, Nerve segment of a Wld ${ }^{\mathrm{S}}$ mouse. Note the macrophage invasion (black staining, arrows) in lesioned normal and IL- $6^{-1-}$ mice (black staining, arrows), which is reduced in Wld ${ }^{\mathrm{S}}$ mice $(D)$.

sensory impairments as well as impairments of regeneration of sensory functions in the sciatic nerve.

In a first approach to estimate effects of IL-6 in the peripheral nervous system, CAPs were recorded from the intact sciatic nerve. The conduction velocities and refractory properties of the CAPs were similar in intact IL- $6^{-/-}$mutants and in IL- $6^{+/+}$ mice (Table 1). In regenerating nerves, conduction velocities were reduced by the same magnitude in $\mathrm{IL}-6^{-1-}$ mutants and wildtype IL- $6^{+/+}$mice. The reduced speed of action potential propagation can be explained by smaller distances between the nodes of Ranvier and by smaller fiber diameters of the regenerating myelinated axons (see e.g., Ritchie, 1982). Furthermore, in both types of regenerating nerves, the refractory period was consistently increased (also see Ritchie, 1982). This was reflected by the decreased ratios of the amplitudes of the CAP elicited by a second pulse applied with a delay of $3.6 \mathrm{msec}$ (within the relative refractory period) to the amplitude of the CAP elicited by the first stimulation (Table 1). This finding indicates that in IL- $^{-/-}$ mutants, no major differences in ion channel regulation occur as compared with wild-type IL- $6^{+/+}$mice, neither in intact nor in regenerating nerves.

Yet specific differences between IL- $6^{+/+}$and IL- $6^{-/-}$mutants were observed in the sensory branches of the sciatic nerves. In the intact nerves the amplitudes of the CAPs of sensory and motor branches were of the same magnitude as in control mice. However, in IL- $6^{-1-}$ mice, the amplitudes of the sensory CAPs were selectively reduced by $60 \%$ as compared with those of motor branches, which could be explained by a reduced number of functional sensory axons (Fig. 1). Furthermore, the relative size distribution of the cross-sectional area of the sensory neurons was shifted to smaller values, and the heat sensitivity was reduced (Fig. 2). To investigate the reasons for the reduced heat sensitivity, the absolute numbers of sensory neurons, especially those of the small-diameter pain sensitive neurons, would have to be determined rather than the shifts in relative sizes. Moreover, it remains to be analyzed in detail whether the relationships between cell soma sizes and specific sensory functions are maintained in the IL- $6^{-1-}$ mice. Nevertheless, our results indicate that the development or maintenance of multiple sensory functions are downregulated in IL- $6^{-1-}$ mice, suggesting a correspondingly supportive role of IL-6 in the normal organism. This assumption is in line with the finding by others that IL-6 promotes the survival of at least a subpopulation of cultured DRG neurons (Murphy et al., 1997).

It has recently been demonstrated that brain-derived neurotrophic factor-dependent enteroceptive neurons of the nodose ganglion are also supported by IL-6 and other related cytokines (Horton et al., 1998). Finally, an intrathecal injection of IL-6 results in a thermal hyperalgesia, i.e., an increased sensitivity to heat stimuli (DeLeo et al., 1996).

Given the sensory deficiencies in intact animals, we challenged the IL- $6^{-1-}$ mice by measuring their capacity of functional regeneration from sciatic nerve lesion. Initially, the behavioral recovery (SFI) was identical between wild-type and IL-6 ${ }^{-1-}$ mice, but after $15 \mathrm{~d}$ it was clearly delayed. This, together with previous results on the regulation of IL-6 synthesis, may imply 
that IL-6 supports the regeneration of peripheral nerves of normal animals: lesions of facial or sciatic nerves lead to a rapid upregulation of IL-6 mRNA levels (Kiefer et al., 1993; Bolin et al., 1995). Crush or cut injury of the sciatic nerve results in increased IL- 6 mRNA levels at the tip of the proximal stump and throughout the distal stump (Zhong and Heumann, 1995; Bizette et al., 1996; Bourde et al., 1996). This spatial distribution of IL-6 mRNA is similar to that of the rapidly induced levels of mRNA coding for nerve growth factor (Heumann et al., 1987a; Zhong and Heumann, 1995).

To approach in more detail the mechanism of the observed delayed functional recovery, we measured selectively the distance of functional regeneration of myelinated sensory and motor axons. Twenty days after crush lesion, the amplitudes of the CAPs were measured in sequential steps distal to the site of lesion. The IL- $6^{-/-}$and IL- $6^{+/+}$wild-type controls showed an identical pattern of regeneration in the motor branch. However, the recovery of the relative CAP amplitudes in the fibers of the sensory branch was clearly delayed in IL- $6^{-1-}$ mice, indicating that fewer peripheral fibers conducted action potentials at $20 \mathrm{~d}$ after lesion (Fig. 6). A preliminary observation at 4 months after crush lesion shows that sensory CAPs recovered in IL- $6^{-1-}$ mice (data not shown), suggesting that there was no general failure of sensory axon regeneration.

Because macrophages and fibroblasts may contribute to lesioninduced IL-6 levels in the nerve, we asked whether the previously described attenuation of IL- 6 production in injured $\mathrm{Wld}^{\mathrm{S}}$ mice would lead to a corresponding IL- $6^{-1-}$-like phenotype (Northemann et al., 1989; Reichert et al., 1996). Accordingly, a similar decrease in sensory recovery of amplitudes of CAPs in the sciatic nerve of Wld ${ }^{\mathrm{S}}$ mutant mice could be confirmed here (Figs. 2, 5, 6) (Brown et al., 1991). This delayed recovery of CAPs in Wld ${ }^{S}$ mutant mice was shown previously to correlate with a reduction in reinnervation success of sensory myelinated axons (Brown et al., 1991). In summary, the similarities we and others find between IL- $6^{-1-}$ and Wld ${ }^{\mathrm{S}}$ mice are as follows. There is a delay of recovery in walking behavior (Chen and Bisby, 1993), a decreased heat sensitivity (Fig. 2), and a decreased recovery of the amplitudes of CAPs in adult sensory myelinated fibers (Fig. 5, 6) (Brown et al., 1991, 1994).

In distinct contrast to $\mathrm{Wld}^{\mathrm{S}}$ mutant mice, however, the lesioninduced massive invasion of macrophages develops indistinguishably between IL- $6^{-/-}$mice and their IL- $6^{+/+}$wild-type counterparts (Fig. 8). Consequently, again at variance with the Wld ${ }^{\mathrm{S}}$ mutant mice, the lesion-induced levels of p75LNTR mRNA (Fig. 7) are identical in IL- $6^{-/-}$mice and the IL- $6^{+/+}$wild-type animals in the distal segments (Heumann et al., 1987b; Brown et al., 1991). The similar and variant phenotypes of Wld ${ }^{\mathrm{S}}$ and IL- $6^{-1-}$ mice may be explained by a reaction of sensory neurons to the common deprivation of lesion-induced IL-6 supply. The variant phenotype may result from contributions by other unknown mechanisms arising from the differences in the mutated targets. Wld ${ }^{\mathrm{S}}$ mutant mice carry a tandem triplication in chromosome 4 (Coleman et al., 1998), whereas the gene knockout mutation is located in chromosome 5 (Mock et al., 1989). This may also explain the observation that the sensory deficiencies found in IL- $6^{-/-}$mice were less pronounced as compared with those of $\mathrm{Wld}^{\mathrm{S}}$ mice, although the latter are still able to produce some IL-6 (Reichert et al., 1996).

In the CNS there is clear evidence that IL- 6 regulates proliferation and function of non-neuronal cells. Genetically modified mice overexpressing IL-6 in the brain develop astrocytosis and proliferation of ramified microglia (Fattori et al., 1995; Barnum et al., 1996). Similarly, but in contrast to our findings, compensatory proinflammatory reactions have been suggested to explain a hyperalgesic effect in IL-6 ${ }^{-/-}$mice (Xu et al., 1997). However, others have shown that in IL- $6^{-1-}$ mice activation of astrocytes is completely abolished in the facial nucleus after motoneuron axotomy (Klein et al., 1997), which argues against a proinflammatory compensation in IL- $6^{-1-}$ mice. Rather, it cannot be excluded here that, e.g., a reduced release of sciatic Schwann cell-derived factors may be involved in the establishment of the sensory impairments in IL- $6^{-1-}$ mice.

In this study we focussed on peripheral sensory neuron deficiencies. Whether motoneurons are affected in addition remains to be investigated, especially during development. Myelinated regenerating motoneurons are not obviously affected in the sciatic nerve, and this fits with the observation that IL-6 was shown to be ineffective in promoting spinal motoneuron survival after axotomy ( $\mathrm{Li}$ et al., 1994). In addition, in lesioned IL-6 ${ }^{-/-}$mice there could be a compensatory activation of the more generally expressed gp130 receptor by other ligands, especially by CT-1 or LIF, whose synthesis is upregulated in the local environment of responsive motoneurons (Li et al., 1995; Kurek et al., 1996; Arce et al., 1998). Altogether, our results show that IL-6 is essential for the full development of peripheral sensory functions and regeneration.

\section{REFERENCES}

Akira S, Kishimoto T (1996) Role of interleukin-6 in macrophage function. Curr Opin Hematol 3:87-93.

Akira S, Hirano T, Taga T, Kishimoto T (1990) Biology of multifunctional cytokines: IL- 6 and related molecules (IL 1 and TNF). FASEB J 4:2860-2867.

Arce V, Pollock RA, Philippe JM, Pennica D, Henderson CE, deLapeyrière O (1998) Synergistic effects of Schwann- and muscle-derived factors on motoneuron survival involve GDNF and cardiotrophin-1 (CT-1). J Neurosci 18:1440-1448.

Austyn JM, Gordon S (1981) F4/80: a monoclonal antibody directed specifically against the mouse macrophage. Eur J Immunol 10:805-815.

Barnum SR, Jones JL, Müller-Ladner U, Samimi A, Campbell IL (1996) Chronic complement $\mathrm{C} 3$ gene expression in the CNS of transgenic mice with astrocyte-targeted interleukin-6 expression. Glia 18:107-117.

Bizette C, Chan-Chi-Song P, Fontaine M, Tadie M (1996) Expression of mRNA, interleukin-1 beta, interleukin 6 and tumor necrosis factoralpha during regeneration of the sciatic nerve in rats after tissue loss. Chirugie 121:474-481.

Bolin LM, Verity AN, Silver JE, Shooter EM, Abrams JS (1995) Interleukin-6 production by Schwann cells and induction in sciatic nerve injury. J Neurochem 64:850-858.

Bourde O, Kiefer R, Toyka KV, Hartung HP (1996) Quantification of interleukin-6 mRNA in wallerian degeneration by competitive reverse transcription polymerase chain reaction. J Neuroimmunol 69:135-140.

Brown MC, Perry VH, Lunn ER, Gordon S, Heumann R (1991) Macrophage dependence of peripheral sensory nerve regeneration: possible involvement of nerve growth factor. Neuron 6:359-370.

Brown MC, Perry VH, Hunt SP, Lapper SR (1994) Further studies on motor and sensory nerve regeneration in mice with delayed Wallerian degeneration. Eur J Neurosci 6:420-428.

Campbell IL (1998) Transgenic mice and cytokine actions in the brain: bridging the gap between structural and functional neuropathology. Brain Res Brain Res Rev 26:327-336.

Campbell IL, Abraham CR, Masliah E, Kemper P, Inglis JD, Oldstone MBA, Mucke L (1993) Neurologic disease induced in transgenic mice by cerebral overexpression of interleukin 6. Proc Natl Acad Sci USA 90:10061-10065.

Chen S, Bisby MA (1993) Impaired motor axon regeneration in the C57BL/Ola mouse. J Comp Neurol 333:449-454.

Chomczynski P, Sacchi N (1987) Single step method of RNA isolation by acid guanidinium thiocyanate-phenol-chloroform extraction. Anal Biochem 161:156-159. 
Coleman MP, Conforti L, Buckmaster EA, Tarlton A, Ewing RM, Brown MC, Lyon MF, Perry VH (1998) An 85-kb tandem triplication in the slow wallerian degeneration (Wlds) mouse. Proc Natl Acad Sci USA 95:9985-9990.

De Medinaceli L, Freed WJ, Wyatt RJ (1982) An index of the functional condition of rat sciatic nerve based on measurements made from walking tracks. Exp Neurol 77:634-643.

DeLeo JA, Colburn RW, Nichols M, Malhotra A (1996) Interleukin-6mediated hyperalgesia/allodynia and increased spinal IL-6 expression in a rat mononeuropathy model. J Interferon Cytokine Res 16:695-700.

Fattori E, Lazzaro D, Musiani P, Modesti A, Alonzi T, Ciliberto G (1995) IL-6 expression in neurons of transgenic mice causes reactive astrocytosis and increase in ramified microglial cells but no neuronal damage. Eur J Neurosci 7:2441-2449.

Gadient RA, Otten U (1994) Expression of interleukin-6 (IL-6) and interleukin-6 receptor (IL-6R) mRNA in rat brain during postnatal development. Brain Res 637:10-14.

Gadient RA, Otten U (1996) Postnatal expression of interleukin-6 (IL-6) and IL-6 receptor (IL-6R) mRNAs in rat sympathetic and sensory ganglia. Brain Res 724:41-46.

Gadient RA, Otten UH (1997) Interleukin-6 (IL-6): A molecule with both beneficial and destructive potential. Prog Neurobiol 52:379-390.

Gruol DL, Nelson TE (1997) Physiological and pathological roles of interleukin-6 in the central nervous system. Mol Neurobiol 15:307-339.

Hama T, Kushima Y, Miyamoto M, Kubota M, Takei N, Hatanaka H (1991) Interleukin-6 improves the survival of mesencephalic catecholaminergic and septal cholinergic neurons from postnatal, twoweek-old rats in cultures. Neuroscience 40:445-452.

Heinrich PC, Horn F, Graeve L, Dittrich E, Kerr I, Muller-Newen G, Grotzinger J, Wollmer A (1998) Interleukin-6 and related cytokines: effect on the acute phase reaction. Z Ernährungswiss [Suppl] 37:43-49.

Heumann R, Korsching C, Bandtlow C, Thoenen H (1987a) Changes in nerve growth factor synthesis in nonneural cells in response to sciatic nerve transection. J Cell Biol 104:1623-1631.

Heumann R, Lindholm D, Bandtlow C, Meyer M, Radeke MJ, Misko TP, Shooter ME, Thoenen H (1987b) Differential regulation of mRNA encoding nerve growth factor and its receptor in rat sciatic nerve during development, degeneration, and regeneration: role of macrophages. Proc Natl Acad Sci USA 84:8735-8759.

Hirano T, Yasujawa K, Harada H, Taga T, Watanabe Y, Matsuda T, Kashiwamura S, Nakajima K, Koyama K, Iwamatsu A, Tsunasawa S, Sakiyama F, Matsui H, Takahara Y, Taniguchi T, Kishimoto T (1986) Complementary DNA for a novel human interleukin (BSF-2) that induces B lymphocytes to produce immunoglobulin. Nature 324:73-76.

Hirano T, Nakajima K, Hibi M (1997) Signaling mechanisms through gp130: a model of the cytokine system. Cytokine Growth Factor Rev 8:241-252.

Horton AR, Bartlett PF, Pennica D, Davies AM (1998) Cytokines promote the survival of mouse cranial sensory neurones at different developmental stages. Eur J Neurosci 10:673-679.

Ikeda K, Iwasaki Y, Shiojima T, Kinoshita M (1996) Neuroprotective effect of various cytokines on developing spinal motoneurons following axotomy. J Neurol Sci 135:109-113.

Ip NY, Nye SH, Boulton TG, Davies S, Taga T, Li Y, Birren SJ, Yasukawa K, Kishimoto T, Anderson DJ, Stahl N, Yancopoulos GD (1992) CNTF and LIF act on neuronal cells via shared signaling pathways that involve the IL-6 signal transducing receptor component gp130. Cell 69:1121-1132.

Kiefer R, Lindholm D, Kreutzberg GW (1993) Interleukin-6 and transforming growth factor- $1 \beta$ mRNAs are induced in rat facial nucleus following motoneuron axotomy. Eur J Neurosci 5:775-781.

Kishimoto T, Taga T, Akira S (1992) Cytokine signal transduction. Cell 76:253-262.

Klein MA, Möller JC, Jones LL, Bluethmann H, Kreutzberg GW, Raivich G (1997) Impaired neuroglial activation in interleukin-6 deficient mice. Glia 19:227-233.
Kopf M, Baumann H, Freer G, Freudenberg M, Lamers M, Kishimoto T, Zinkernagel R, Bluethmann H, Köhler G (1994) Impaired immune and acute-phase responses in interleukin-6-deficient mice. Nature 368:339-342.

Kurek JB, Nouri S, Kannourakis G, Murphy M, Austin L (1996) Leukemia inhibitory factor and interleukin-6 are produced by diseased and regenerating skeletal muscle. Muscle Nerve 19:1291-1301.

Kushima Y, Hatanaka H (1992) Interleukin-6 and leukemia inhibitory factor promote the survival of acetylcholinesterase-positive neurons in culture from embryonic rat spinal cord. Neurosci Lett 143:110-114.

Kushima Y, Hama T, Hatanaka H (1992) Interleukin-6 as a neurotrophic factor for promoting the survival of cultured catecholaminergic neurons in a chemically defined medium from fetal and postnatal rat midbrains. Neurosci Res 13:267-280.

Li L, Oppenheim RW, Lei M, Houenou LJ (1994) Neurotrophic agents prevent motoneuron death following sciatic nerve section in the neonatal mouse. J Neurobiol 25:759-766.

Li M, Sendtner M, Smith A (1995) Essential function of LIF receptor in motor neurons. Nature 378:724-727.

Lindberg RA, Juan TSC, Welcher AA, Sun Y, Cupples R, Guthrie B, Fletcher FA (1998) Cloning and characterization of a specific receptor for mouse oncostatin M. Mol Cell Biol 18:3357-3367.

Lunn ER, Perry VH, Brown MC, Rosen H, Gordon S (1989) Absence of Wallerian degeneration does not hinder regeneration in peripheral nerve. Eur J Neurosci 1:27-33.

März P, Cheng JG, Gadient RA, Patterson PH, Stoyan T, Otten U, Rose-John S (1998) Sympathetic neurons can produce and respond to interleukin-6. Proc Natl Acad Sci USA 95:3251-3256.

Mehler MF, Kessler JA (1997) Hematolymphopoietic and inflammatory cytokines in neural development. Trends Neurosci 20:357-365.

Mock BA, Nordan RP, Justice MJ, Kozak C, Jenkins NA, Copeland NG, Clark SC, Wong GG, Rudikoff S (1989) The murine IL-6 gene maps to the proximal region of chromosome 5. J Immunol 142:1372-1376.

Murphy PG, Grondin J, Altares M, Richardson PM (1995) Induction of interleukin-6 in axotomized sensory neurons. J Neurosci 15:5130-5138.

Murphy PG, Altares M, Gauldie J, Richardson PM (1997) Interleukin-6 promotes survival of sensory neurons. Soc Neurosci Abstr 23:890.

Northemann W, Braciak TA, Hattori M, Lee F, Fey GH (1989) Structure of the rat interleukin- 6 gene and its expression in macrophagederived cells. J Biol Chem 264:16072-16082.

Pennica D, Shaw KJ, Swanson TA, Moore MW, Shelton DL, Zioncheck KA, Rosenthal A, Taga T, Paoni NF, Wood WI (1995) Cardiotrophin-1: biological activities and binding to the leukemia inhibitory factor receptor gp130 signaling complex. J Biol Chem 270:10915-10922.

Ramsay AJ, Kopf M (1998) IL-6 gene knockout mice. In: Cytokine knockouts (Durum SK, Muegge K, eds), pp 227-236. Totowa, NJ: Humana.

Reichert F, Levitzky R, Rotshenker S (1996) Interleukin-6 in intact and injured mouse peripheral nerves. Eur J Neurosci 8:530-535.

Ritchie JM (1982) Sodium and potassium channels in regenerating and developing mammalian myelinated nerves. Proc R Soc Lond B Biol Sci 215:273-287.

Sterneck E, Kaplan DR, Johnson PF (1996) Interleukin-6 induces expression of peripherin and cooperates with Trk receptor signaling to promote neuronal differentiation in $\mathrm{PC} 12$ cells. J Neurochem 67:1365-1374.

Vallières L, Rivest S (1997) Regulation of the genes encoding interleukin-6, its receptor, and gp130 in the rat brain in response to the immune activator lipopolysaccharide and the proinflammatory cytokine interleukin-1 $\beta$. J Neurochem 69:1668-1683.

Xu X-J, Hao J-X, Andell-Jonsson S, Poli V, Bartfai T, Wiesenfeld-Hallin Z (1997) Nociceptive responses in interleukin-6-deficient mice to peripheral inflammation and peripheral nerve section. Cytokine 9:1028-1033.

Zhong J, Heumann R (1995) Lesion-induced interleukin-6-mRNA expression in rat sciatic nerve. Ann NY Acad Sci 762:488-490. 